\title{
Increasing Charpy Impact Value of Polycarbonate (PC) Sheets Irradiated by Electron Beam
}

\author{
Yoshitake Nishi ${ }^{1}$, Michael C. Faudree ${ }^{2}$, Junhua Quan ${ }^{1}$, Yoshiaki Yamazaki ${ }^{1}$, Anna Takahashi ${ }^{1}$, \\ Syohei Ogawa ${ }^{1}$, Keisuke Iwata ${ }^{1}$, Akira Tonegawa ${ }^{3}$ and Michelle Salvia ${ }^{4}$ \\ ${ }^{1}$ Graduate School of Materials Engineering, Tokai University, Hiratsuka 259-1292, Japan \\ ${ }^{2}$ Faculty of Liberal Arts and Sciences, Tokyo City University, Yokohama 224-8551, Japan \\ ${ }^{3}$ Graduate School of Science \& Technology, Tokai University, Hiratsuka 259-1292, Japan \\ ${ }^{4}$ LTDS, Ecole Centrale de Lyon, Ecully Cedex 69134, France
}

Applying low-potential electron beam irradiation (EBI) dose of $0.13 \mathrm{MGy}$ to polycarbonate (PC) sheet on both side surfaces apparently improved the impact value $\left(a_{\mathrm{uc}}\right)$ over the untreated samples at all accumulative probabilities of fracture $\left(P_{\mathrm{f}}\right)$. Based on 3-parameter Weibull equation, the $0.13 \mathrm{MGy}-\mathrm{EBI}$ also raised the lowest limit of $a_{\mathrm{uc}}\left(25.5 \mathrm{~kJ} \mathrm{~m}^{-2}\right)$ estimated at $P_{\mathrm{f}}=0\left(a_{\mathrm{s}}\right) 14 \%$ over the untreated samples $\left(22.0 \mathrm{~kJ} \mathrm{~m}^{-2}\right)$, indicating improved reliability and safety. EBI generates dangling bonds where repulsive forces are generated between the outer shell electrons at terminated atoms in the PC polymer irradiated near the sample surface, probably inducing relaxation of heterogeneous stress concentration, as well as compressive stress (high molecular density) by micro-expansion around terminated atoms increasing the $a_{\mathrm{uc}}$. Increasing EBI dose increased ductility by decreasing the fractured split ratio, $R_{\mathrm{s}}$ a characterization of separated portion of total cross-section of fractured PC. The $0.13 \mathrm{MGy}$ dose $\left(R_{\mathrm{s}}=0.30\right)$ appears to be at or near the optimal EBI dose obtaining the highest $a_{\mathrm{uc}}$. Above $0.22 \mathrm{MGy}$ the $a_{\mathrm{uc}}$ reduces with increasing dose. Excessive dangling bonds generation appeared to increase ductility in the form of lowering the $R_{\mathrm{S}}$ but weakens the molecular structure allowing chains to slide past each other easier decreasing impact values with less crack propagation. Therefore, when applying EBI to polycarbonate parts in industrial applications carefulness is highly recommended to adjust dose to optimal level for maximum strength and safety. [doi:10.2320/matertrans.M2018095]

(Received March 20, 2018; Accepted May 22, 2018; Published June 29, 2018)

Keywords: polycarbonate, ductility, electron beam, irradiation, Charpy impact test

\section{Introduction}

The strengthening of light structural materials has been always required to develop high-speed transport vehicles with safety enhancement and low energy consumption. The structural formula of polycarbonate (PC) polymers includes two carbocyclic six-membered aromatic rings ${ }^{1)}$ which are the main parts composing its strong molecular segments. PC exhibits high wear resistance as well as high strength and fracture toughness. It can be utilized for optical lenses, CD substrates, in electromagnetic wave shielding materials, as well as artificial body parts. When used as windows for vehicles, PC provides weight savings having lower density than glass. PC is also a promising material for electric car bodies reducing weight significantly improving efficiency eco-friendly to our environment. Therefore, further strengthening with reliability enhancement is always desired.

When the magnetic lens focuses the electron beam irradiation (EBI) with high voltage, it easily induces radiation damage in polymers as well as metals. On the other hand, homogeneously applying a lower dose on the order of $100 \mathrm{kV}$, referred to as homogeneous low-voltage electron beam (EBI), ${ }^{2-5)}$ makes it easy to migrate the surface atoms generating point defects in crystal and free volume in glassy materials. EBI has a positive record of improving many solid materials including mist resistance with wetting, ${ }^{2-5}$ ) adhesion, ${ }^{6-15)}$ sterilization ${ }^{16)}$ and strengthening, ${ }^{1,17-30)}$ as well as both wear resistance and industrially utilized burnishing. Since the stability and homogeneity of industrial EBI equipment are tremendously high, they have been practically utilized for wallpaper sheet, building insulation and automotive parts up to several square meters in size.
In 2003, enhancements of bending fracture strength and its strain of epoxy polymer, generally utilized for matrix of carbon fiber reinforced polymer (CFRP) have been reported. ${ }^{20)}$ Furthermore, for polycarbonate (PC) extremely low optimum dose of $0.02 \mathrm{MGy}-\mathrm{EBI}$ was found to enhance stiffness over $100 \%$, upper yield stress $\sim 12 \%$, lower yield stress $\sim 12 \%$, tensile fracture strength $\sim 20 \%$ and its strain $\sim 16 \%$, although increased dose of more than $0.10 \mathrm{MGy}-\mathrm{EBI}$ decayed these mechanical properties. ${ }^{30)}$

It follows high impact resistance is important to protect aircraft, automobiles and other applications from projectiles such as bird strike, volcanic rock or hailstone. Given the improvements in tensile properties of PC by EBI, it is hypothesized EBI can improve the impact resistance of the PC polymer 10 to $20 \%$ for practical use. Therefore, the purpose of the present work is to evaluate the effect of EBI on the impact value of the PC for application to aircraft windows and high-speed mover machines.

\section{Experimental Procedure}

\subsection{Condition of EB-irradiation}

Prior to HLEBI treatment, non-reinforced PC (TAKIRON INC, Tokyo) polymer samples were cut to dimensions $1.0 \times 80 \times 10 \mathrm{~mm}\left(\right.$ volume $\left.=800 \mathrm{~mm}^{3}\right)$. The sheet samples were then homogeneously treated by the prototype equipment known as the electron-curtain processor (Type CB175/ 15/180L, Energy Science Inc., Woburn, MA), which was constructed with a vacuum chamber $(240 \mathrm{~mm}$ in diameter under $\left.10^{-5} \mathrm{~Pa}\right)$ with a tungsten filament $(215 \mathrm{~mm}$ length $)$ and a thin titanium window $(150 \mathrm{~mm}$ length, $150 \mathrm{~mm}$ width and $0.01 \mu \mathrm{m}$ thickness), and sample treatment compartment with conveyer under $1 \mathrm{~atm} \mathrm{~N}_{2}(\mathrm{~g}) .^{1-15,17-30)}$ 
The sheet specimen was homogeneously irradiated with the electron beam through the titanium thin film window attached to the vacuum chamber. The tungsten filament in vacuum was used to generate the electron beam at a low energy (acceleration potential, $V: \mathrm{kV}$ ), of $170 \mathrm{kV}$ and irradiating current density $\left(J: \mathrm{Am}^{-2}\right)$ of $0.089 \mathrm{Am}^{-2}$. Although the electron beam generation was in a vacuum, the irradiated sample was kept under protective $1 \mathrm{~atm} \mathrm{~N}_{2}(\mathrm{~g})$. The distance between sample and window was $35 \mathrm{~mm}$. To prevent oxidation, the samples were kept in the protective $1 \mathrm{~atm} \mathrm{~N}_{2}$ with an $\mathrm{O}_{2}$ residual concentration below $400 \mathrm{ppm}$. The flow rate of the $\mathrm{N}_{2}$ was $1.5 \mathrm{Ls}^{-1}$ at $0.1 \mathrm{MPa}$ of $\mathrm{N}_{2}$ gas pressure.

Each sweep of irradiation dose $\left(0.043 \mathrm{MGy}\left(\mathrm{kJ} \mathrm{g}^{-1}\right)\right)$ was applied for only a short time $(0.23 \mathrm{~s})$ to avoid excessive heating of the sample; the temperature of the sample surface remained below $323 \mathrm{~K}$ just after irradiation. The sample in the aluminum plate holder $(0.15 \mathrm{~m} \times 0.15 \mathrm{~m})$ was transported on a conveyor at a speed of $10.0 \mathrm{~m} \mathrm{~min}^{-1}$. The sheet electron beam irradiation was applied intermittently. Repeated irradiations to both side surfaces of the samples were used to increase the total dose of irradiation. The interval between the end of one period of irradiation sweep and the start of the next was $30 \mathrm{~s}$.

When the irradiation current (I: $\mathrm{mA})$, the conveyor speed $\left(S: \mathrm{m} \mathrm{min}^{-1}\right)$, and number of irradiations $(N)$ are determined, the irradiated dose ( $D$ : MGy) is expressed by the following equation:

$$
\text { Dosage }(\mathrm{MGy})=0.216 \times(I / S) \times N
$$

The irradiation dose has been controlled by the integrated irradiation time in each of the samples. Here, irradiation dose has been corrected by using an FWT nylon dosimeter of RCD radiometer film (FWT-60-00: Far West Technology, Inc. 330-D South Kellogg Goleta, California 93117, USA) with an irradiation reader (FWT-92D: Far West Technology, Inc. 330-D South Kellogg Goleta, California 93117, USA). The dose is $0.0432 \mathrm{MGy}$ at each irradiation. Based on the mean density $\left(\rho: \mathrm{kg} / \mathrm{m}^{3}\right)$ and irradiation potential at the specimen surface $(V: \mathrm{keV})$, the penetration depth $\left(D_{\mathrm{th}}: \mu \mathrm{m}\right)$ of EB-irradiation is expressed by the following equation. $^{20)}$

$$
D_{\text {th }}=66.7 V^{5 / 3} / \rho
$$

Specimen surface electrical potential $(V)$ was mainly reduced going through the $\mathrm{Ti}$ window $\left(\Delta V_{\mathrm{Ti}}\right)$ and $\mathrm{N}_{2}$ gas atmosphere $\left(\Delta V_{\mathrm{N} 2}\right)$.

$$
V=170 \mathrm{keV}-\Delta V_{\mathrm{Ti}}-\Delta V_{\mathrm{N} 2}
$$

Based on eq. (2), the dropped potential values, $\Delta V_{\mathrm{Ti}}$ and $\Delta V_{\mathrm{N} 2}$ are estimated from the acceleration potential $(170 \mathrm{keV})$, the $13 \mu \mathrm{m}$ thickness $\left(T_{\mathrm{Ti}}\right)$ of the titanium window (density: $4540 \mathrm{~kg} \cdot \mathrm{m}^{-3}$ ), and the $25 \mathrm{~mm}$ distance between the sample and the window $\left(T_{\mathrm{N} 2}\right)$ in the $\mathrm{N}_{2}$ gas atmosphere (density: $\left.\rho_{\mathrm{N} 2}=1.13 \mathrm{~kg} \cdot \mathrm{m}^{-3}\right)$.

$$
\begin{aligned}
\Delta V_{\mathrm{Ti}} & =T_{\mathrm{Ti}} / \mathrm{D}_{\mathrm{thTi}} \times 170 \mathrm{keV} \\
& =T_{\mathrm{Ti}} \rho_{\mathrm{Ti}} /\left[66.7 \times(170 \mathrm{keV})^{2 / 3}\right] \\
& =(10 \mu \mathrm{m}) \times\left(4540 \mathrm{~kg} \mathrm{~m}^{-3}\right) /\left[66.7 \times(170 \mathrm{keV})^{2 / 3}\right] \\
& =22.2 \mathrm{keV}
\end{aligned}
$$

$$
\begin{aligned}
\Delta V_{\mathrm{N} 2}= & \left(T_{\mathrm{N} 2} / D_{\mathrm{thiN} 2}\right) \times V_{\mathrm{Ti}} \\
= & T_{\mathrm{N} 2} \rho_{\mathrm{N} 2} /\left[66.7 \times\left(170 \mathrm{keV}-\Delta V_{\mathrm{Ti}}\right)^{2 / 3}\right] \\
= & \left(25 \times 10^{3} \mathrm{~m}\right) \\
& \times\left(1.13 \mathrm{~kg} \mathrm{~m}^{-3}\right) /\left[66.7 \times(170 \mathrm{keV}-22.2 \mathrm{keV})^{2 / 3}\right] \\
= & 15.2 \mathrm{keV}
\end{aligned}
$$

Since the dropped potential values are $22.2 \mathrm{keV}$ and $15.2 \mathrm{keV}$, the specimen surface electrical potential, $V$ is obtained to be $132.6 \mathrm{keV}$ as follows.

$$
\mathrm{V}=170 \mathrm{keV}-22.2 \mathrm{keV}-15.2 \mathrm{keV}=132.6 \mathrm{keV}
$$

Based on the eq. (2) and the density is $1.20 \mathrm{~g} / \mathrm{cm}^{3}$ of the PC samples, the penetration depth $\left(D_{\mathrm{th}}: \mu \mathrm{m}\right)$ is $191 \mu \mathrm{m}$.

\subsection{Samples and Charpy impact test}

Usually, damage by a hemispherical impactor is initiated as a point force on the center of a square or rectangular specimen $\sim 70$ to $150 \mathrm{~mm}^{2}$ by slow point force, ${ }^{31)}$ drop tower, or projectile. ${ }^{32-35)}$ For low energy tests, impact is followed by non-destructive testing (NDT) with an ultrasonic transducer to detect delamination undetectable to the eye which can reduce strength significantly. Compression after impact (CAI) testing is often conducted after point impact in aerospace materials such as quasi-isotropic CFRP for safety design, ${ }^{36,37)}$ and is generally utilized to evaluate safety against impact accidents such as bird strike, volcanic rock or hailstone on aircraft CFRP. ${ }^{38,39)}$ On the other hand, Charpy impact test employs a drop-weight pendulum and evaluates impact absorption characteristics and relative impact toughness of materials often used in quality control applications utilized as a low-cost and rapid way to estimate reaction to higher velocity impact. We do not claim the Charpy test to be a substitute for point impact followed by compression after impact (CAI). However, Charpy impact method could possibly be used as an inexpensive preliminary evaluation to screen candidate materials to later test with indentation or projectile followed by CAI. Hence, Charpy may give a rough or better estimation of which materials and what temperatures a projectile such as bird strike, volcanic rock or hailstone will cause the most damage. Tests are carried out calibrating for air friction and effect of air temperature and humidity on the swing and pivot of the pendulum. Therefore, the velocity, $v\left(\mathrm{~ms}^{-1}\right)$ and kinetic energy, $K E(\mathrm{~J})$ hitting the sample are assumed to be approximately constant similar to comparing projectiles in a point impact test hitting the composite surface at constant $v$ and $K E$. Thus, when the Charpy impact test impact velocity, $v$ hitting the sample is calculated as: ${ }^{40)}$

$$
v=[2 g R(1-\cos \alpha)]^{0.5}
$$

where $g$ is gravitational constant $\left(9.8 \mathrm{~ms}^{-2}\right), R$ is length (m) of hammer weight point from rolling center $(0.21 \mathrm{~m})$, and $\alpha$ is start angle before impact $\left(2.3\right.$ Radians, $\left.132^{\circ}\right)$, then $v$ of the hammer hitting the specimen is $\sim 1.74 \mathrm{~ms}^{-1}(\sim 3.89 \mathrm{mi} / \mathrm{hr})$. Potential energy $(P E)(\mathrm{J})$ of impact is: ${ }^{40)}$

$$
P E=R(1-\cos \alpha) F
$$

where $F$ is measured supporting force $(\mathrm{N})$ exerted by the pendulum in the horizontal position. $P E$ is assumed to be equivalent to the $K E$ in the horizontal vector, $0.5 m v^{2}$, or $1.30 \mathrm{~J}\left(1.3 \times 10^{-3} \mathrm{~kJ}\right)$. The surface area of the impactor tip 
is small with circular shaped $\sim 0.5 \mathrm{~mm}$ diameter, so $K E / A$ is large.

In order to evaluate the impact fracture toughness, the Charpy impact values of the PC samples using a standard impact fracture energy measurement system (Shimadzu Corporation No. 51735) (JIS K 7077) ${ }^{41)}$ was utilized. ${ }^{1,21-30)}$ EBI were performed on both side surfaces of the PC samples.

The impact fracture energy $(E)$ is expressed by eq. (9): ${ }^{29)}$

$$
\begin{aligned}
E= & W R[(\cos \beta-\cos \alpha) \\
& \left.-\left(\cos \alpha^{\prime}-\cos \alpha\right)(\alpha+\beta) /\left(\alpha+\alpha^{\prime}\right)\right]
\end{aligned}
$$

Here, $E, W, R, \beta, \alpha$ and $\alpha^{\prime}$ are impact fracture energy (J), hammer weight $(8.43 \mathrm{~N})$, length $(\mathrm{m})$ of hammer weight point from rolling center, the maximum angle after impact, start angle before impact, and the maximum angle of the blank test (for calibration), respectively. The Charpy impact value $\left(a_{\mathrm{uc}}: \mathrm{kJ} \mathrm{m}^{-2}\right)$ is expressed by the following equation. ${ }^{29)}$

$$
a_{\mathrm{uc}}=E /(b t) \times 10^{3}
$$

Here, $E, b(=10 \pm 0.2 \mathrm{~mm})$ and $t(=2.8 \mathrm{~mm})$ are impact fracture energy $(\mathrm{J})$, sample width $(\mathrm{mm})$, and span distance (sample thickness, $\mathrm{mm}$ ), respectively. The distance between supporting points was $40 \mathrm{~mm}$.

Evaluating the cumulative probability of fracture $\left(P_{\mathrm{f}}\right)$ is a convenient method of quantitatively analyzing experimental values, and in industry is often employed in statistical quality control (QC). $P_{\mathrm{f}}$ is expressed by the following equation which is a generalized form of the median-rank method: ${ }^{42)}$

$$
P_{\mathrm{f}}=(i-0.3) /\left(N_{\mathrm{s}}+0.4\right)
$$

Here $N_{\mathrm{s}}$ and $i$ are total number of samples and rank order integer of $a_{\mathrm{uc}}$ of each sample, respectively where $i$ is from weakest to strongest. In this case, $N_{\mathrm{s}}=9$ hence when $i$ values are 1,5 , and 9 , their corresponding $P_{\mathrm{f}}$ values are $0.07,0.50$ and 0.93 , respectively.

\section{Results}

Figure 1 shows that $0.13 \mathrm{MGy}-\mathrm{EBI}$ to the PC polymer apparently improves the impact value $\left(a_{\mathrm{uc}}\right) \sim 21 \%$, from 24.6 to $29.8 \mathrm{~kJ} \mathrm{~m}^{-2}$ over the untreated samples at median- $P_{\mathrm{f}}$ of 0.50 ; and from 22.0 to $26.0 \mathrm{~kJ} \mathrm{~m}^{-2}$ at low- $P_{\mathrm{f}}$ of 0.07 indicating reliability of parts is possible. At high- $P_{\mathrm{f}}$ of $0.93, a_{\mathrm{uc}}$ is improved $11.3 \%$ from 44.0 to $49.0 \mathrm{~kJ} \mathrm{~m}^{-2}$. Furthermore, the $0.13 \mathrm{MGy}-\mathrm{EBI}$ apparently improves the $a_{\mathrm{uc}}$ at all $P_{\mathrm{f}}$, while exhibiting a $24 \%$ improvement in average $a_{\mathrm{uc}}$ from 27.3 to $33.8 \mathrm{~kJ} \mathrm{~m}^{-2}$.

Although Fig. 1 shows $a_{\mathrm{uc}}$ is reduced at doses above $0.22 \mathrm{MGy}$, the $0.13 \mathrm{MGy}-\mathrm{EBI}$ appears to be near the optimal dose for the PC as shown in Fig. 1 since the lower and higher EBI doses of 0.04 and $0.22 \mathrm{MGy}$ resulted in unchanged $a_{\mathrm{uc}}$ at low $P_{\mathrm{f}}$ of 0.07 and decreases at the high- $P_{\mathrm{f}}$ of 0.93 ; while higher EBI doses decrease the $a_{\mathrm{uc}}$ further.

\section{Discussion}

\subsection{The lowest impact value, $a_{\mathrm{s}}$ estimated}

The $a_{\mathrm{s}}, a_{\mathrm{uc}}$ value at $P_{\mathrm{f}}=0$ represents the statistically lowest impact value for safety considerations and deems valuable for process with quality control. By applying the

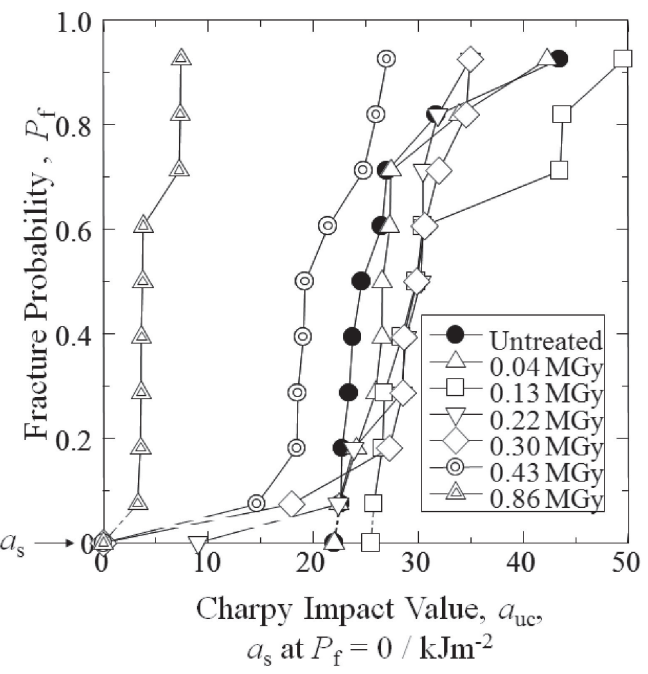

Fig. 1 Changes in experimental impact values, $a_{\mathrm{uc}}\left(\mathrm{kJ} \mathrm{m}^{-2}\right)$ of $\mathrm{PC}$ at each dose of EBI against $P_{\mathrm{f}}$, together with the lowest impact values calculated $\left(a_{\mathrm{s}}=a_{\mathrm{uc}}\right.$ at $\left.P_{\mathrm{f}}=0\right)$.

0.13 MGy EBI to the PC, Fig. 1 shows the $a_{\mathrm{s}}$ estimated by 3 -parameter Weibull equation is improved $14 \%$ over the untreated from 22.0 to $25.5 \mathrm{~kJ} \mathrm{~m}^{-2}$.

Since the experimental $a_{\mathrm{uc}}$ values at lower $P_{\mathrm{f}}$ value have largely deviated from the linear relationship estimated by 2-parameter Weibull equation, ${ }^{26,43)}$ the practical $a_{\text {uc }}$ value at extremely low $P_{\mathrm{f}}$ near zero cannot be precisely estimated. ${ }^{26,43)}$

Hence, when the statistical 3-parameter Weibull equation is assumed to be applicable to the measured $a_{\mathrm{uc}}$ value, the $P_{\mathrm{f}}$ value depends on the risk of rupture $\left(\left[a_{\mathrm{uc}}-a_{\mathrm{s}}\right] / a_{\mathrm{III}}\right)$, as a following equation. ${ }^{26,43)}$

$$
P_{\mathrm{f}}=1-\exp \left[-\left(\left[a_{\mathrm{uc}}-a_{\mathrm{s}}\right] / a_{\mathrm{III}}\right)^{m}\right]
$$

The linear logarithmic form can then be obtained:

$$
\ln \left[-\ln \left(1-P_{\mathrm{f}}\right)\right]=m \ln \left[a_{\mathrm{uc}}-a_{\mathrm{s}}\right]-n \ln a_{\mathrm{III}}
$$

In predicting the required impact value of materials, the $a_{\mathrm{uc}}$ value at $P_{\mathrm{f}}=0\left(a_{\mathrm{s}}\right)$, the constant $\left(a_{\mathrm{III}}\right)$ and 3-parameter Weibull coefficient $(m)$ are key parameters. When the term $\left(\ln \left[-\ln \left(1-P_{\mathrm{f}}\right)\right]\right)$ is zero, the $a_{\mathrm{III}}$ is the $a_{\mathrm{uc}}$.

Figure 2 shows iteration of the linear logarithmic form in eq. (13) for the potential lowest impact value $\left({ }^{\mathrm{e}} a_{\mathrm{s}}\right)$ to get the maximum correlation coefficient $(F)$ corresponding to the $a_{\mathrm{s}}$ of 22.0, 22.0, 25.5, 9.0, and zero $\mathrm{kJ} \mathrm{m}^{-2}$ (arrows) for the untreated, $0.04,0.13,0.22$ and $0.30 \mathrm{MGy}-\mathrm{EBI}$ irradiated samples, respectively, showing high linear correlations of $0.987,0.972,0.977,0.977$ and 0.956 . The resulting linear relationships are plotted in Fig. 3. Note, the $a_{\mathrm{s}}$ at $P_{\mathrm{f}}=0$ are also indicated in Fig. 1 showing the highest was obtained from the $0.13 \mathrm{MGy}-\mathrm{EBI}$ samples. Figures 1 and 2 show at $0.22 \mathrm{MGy}$ and above, the $a_{\mathrm{s}}$ at $P_{\mathrm{f}}=0$ was reduced. Nevertheless, our results show the $0.13 \mathrm{MGy}-\mathrm{EBI}$ can improve the $a_{\mathrm{uc}}$ at $P_{\mathrm{f}}=0\left(a_{\mathrm{s}}\right)$.

Figure 4 shows the 0.13 MGy-EBI was able to successfully enhance the PC polymer across the fracture probability range for selected $P_{\mathrm{f}}$, respectively along with the $a_{\mathrm{s}}$ at $P_{\mathrm{f}}=0$. For doses above $0.13 \mathrm{MGy}$ drops in $a_{\mathrm{uc}}$ with increasing EBI dose indicate the safety consideration needed when optimizing EBI dose. 


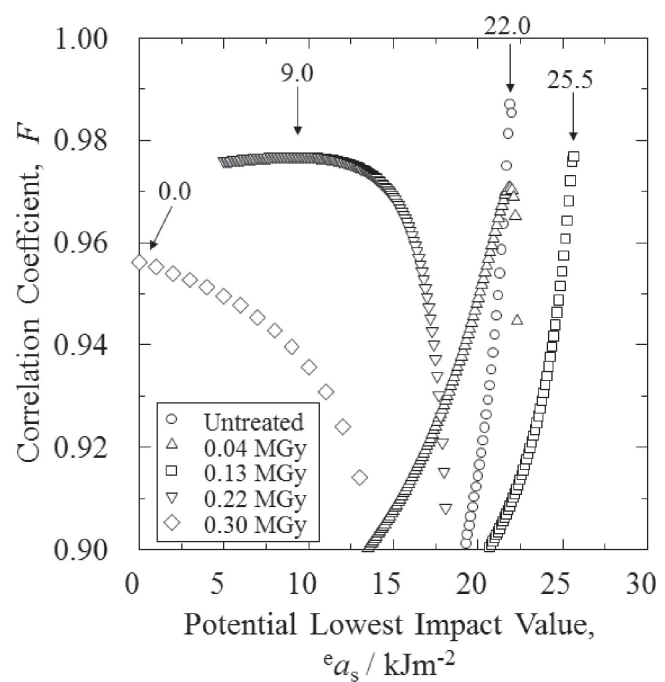

Fig. 2 Changes in the $F$ value of $\mathrm{PC}$ at each dose of EBI against the potential lowest impact value, ${ }^{\mathrm{e}} a_{\mathrm{s}}$

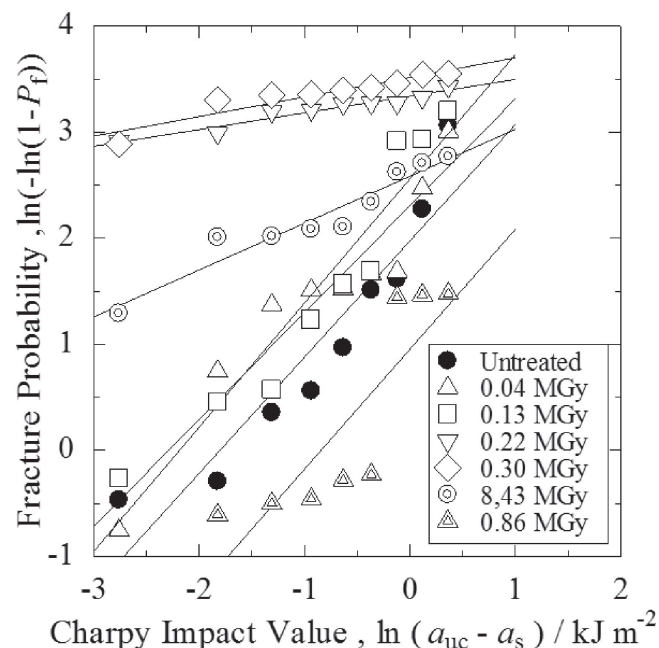

Fig. 3 Relationships between $\ln \left(a_{\mathrm{uc}}-a_{\mathrm{s}}\right)$ vs. $\ln \left[-\ln \left(1-P_{\mathrm{f}}\right)\right]$ for PC at each dose of EBI.

4.2 Optical observations and fractured split ratio, $R_{\mathrm{s}}$ of fractured PC

Observation of the PC samples showed they were partially separated by the impact, exhibiting simple bending fracture at the compressive side accompanied by cracks of a certain area fraction propagating into the thickness from the tensile side.

Therefore, to assess effects of EBI level on brittleness or ductility of the PC samples, we define the fractured split ratio $\left(R_{\mathrm{S}}\right)$ here as separated part of possible total impacted cross-section:

$$
R_{\mathrm{s}}=\left(S_{\mathrm{o}}-S\right) / S_{\mathrm{o}}
$$

where $S_{0}$ and $S$ are total cross-sectional area and nondeformed (undamaged) area, respectively. The lower the $R_{\mathrm{s}}$, the more ductile the fracture mode. Measured split ratio $R_{\mathrm{s}}$, for the $0.13 \mathrm{MGy}-\mathrm{EBI}$ samples is significantly lower $(0.30 \pm 0.10)$ than that of the untreated $(\sim 0.70 \pm 0.10)$ but higher than that $(0.15 \pm 0.05)$ of the $0.86 \mathrm{MGy}$ samples. Thus, increasing EBI dose from zero to $0.86 \mathrm{MGy}$ improves the ductility. However, the $0.13 \mathrm{MGy}-\mathrm{EBI}$ appears to produce

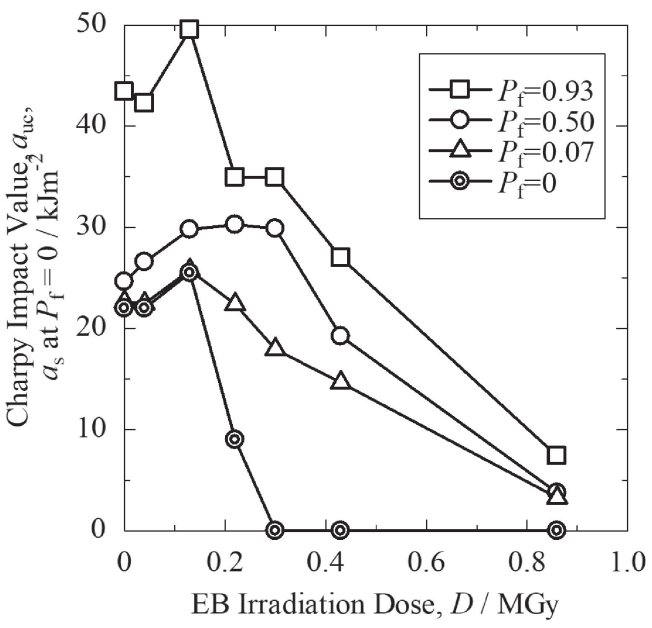

Fig. 4 Changes in Charpy impact values, $a_{\mathrm{uc}}\left(\mathrm{kJ} \mathrm{m}^{-2}\right)$ of $\mathrm{PC}$ at each selected $P_{\mathrm{f}}$, of $0.07,0.50$ and 0.93 against dose (MGy) of EBI.

optimal ductility as evidenced by yielding the highest impact values, $a_{\mathrm{uc}}$ hence being able to withstand maximum absorbed impact energy. At higher doses of $0.86 \mathrm{MGy}, a_{\mathrm{uc}}$ is lowered.

Figures 5(a) and (b) show photographs of fractured PC samples untreated and treated at $0.13 \mathrm{MGy}-\mathrm{EBI}$ at median accumulative probability $\left(P_{\mathrm{f}}=0.50\right)$. Figure 5 shows when impacted (arrows) in the $0.13 \mathrm{MGy}$ sample (b) the crack penetrates at lower depth into the thickness from the tensile side than that of the untreated (a). Crack origins at the tensile side of all specimens are observed to occur accompanied by white crazing. At the compressive side in the untreated and 0.13 MGy samples the white crazing at the impact point was observed to occur, while in the $0.86 \mathrm{MGy}$ samples simple ductile fracture occurs.

\subsection{Effects of EBI on dangling bonds and impact values of PC}

Dangling bonds have been reported to be detected in PC by 0.0216 MGy-EBI irradiation dose as a sharp ESR (electron spin resonance) peak. ${ }^{30)}$ In contrast, it is reported untreated PC does not produce an ESR peak, only a flat line hence no dangling bonds. ${ }^{30)}$ ESR is applied to detect unpaired electrons by their spins $\left(m_{\mathrm{s}}= \pm 1 / 2\right)$. Repulsive forces are generated between the outer shell electrons at terminated atoms irradiated near the sample surface inducing relaxation of heterogeneous stress concentration, as well as compressive stress by micro-expansion around terminated atoms increasing the $a_{\mathrm{uc}}{ }^{30}$ ) However, the high EBI dose of $0.86 \mathrm{MGy}$ while increasing ductility apparently generates excessive dangling bonds allowing chains to slide past each other easier weakening the molecular structure decreasing resistance to impact with less crack propagation. Therefore, the optimum $0.13 \mathrm{MGy}-\mathrm{EBI}$ dose generates the optimum dangling bond density to create micro-compressive forces between atoms increasing impact resistance.

Figure 6 shows schematic illustrations of PC before and after EBI showing terminated atoms with dangling bonds generating repulsive forces ${ }^{30)}$ at high molecular density zone of the polymers. These repulsive forces generate microexpansive stress around dangling bonds sites within and between the PC polymer chains strengthening the PC matrix. 

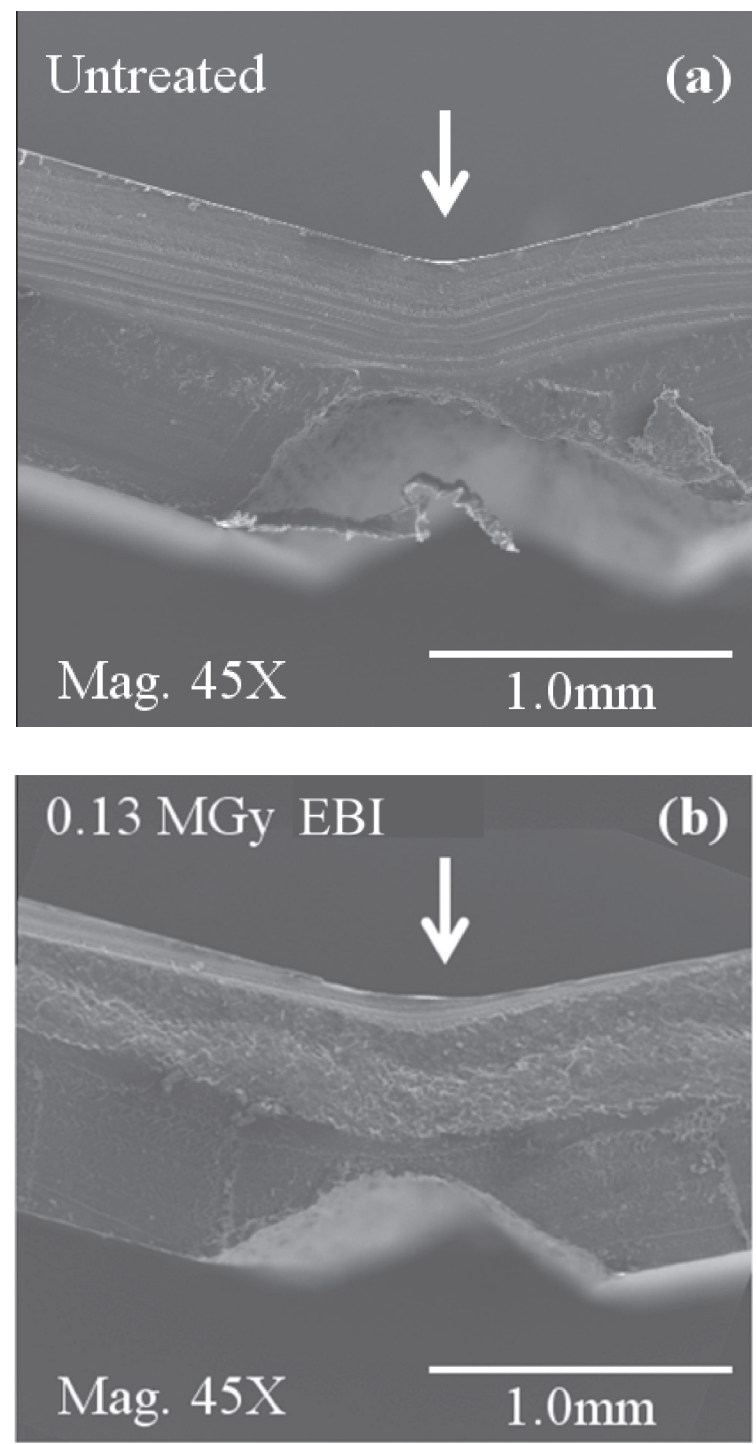

Fig. 5 Photograph of side surfaces of impacted PC samples showing that of (a) untreated and; (b) $0.13 \mathrm{MGy}-\mathrm{EBI}$ treated, both at median accumulative probability $\left(P_{\mathrm{f}}=0.50\right)$. Arrows indicate impact direction.

As shown in Figs. 1 and 4, the 0.13 MGy-EBI dose appears to generate the optimum dangling bond density for increasing the $a_{\mathrm{uc}}$.

Since dangling bond densities in PC are controlled by EBI dose, it is possible to get optimal density of dangling bonds to enhance the $a_{\mathrm{uc}}$. Obtaining the optimum dose of EBI appears to be a useful tool for quick strengthening to get high impact value of PC. However, carefulness is needed in quality control to adjust EBI dose to optimal level for each given situation when treating aircraft and other parts to maximize strength with high safety.

\section{Conclusions}

(1) Applying electron beam irradiation (EBI) dose of 0.13 MGy to PC polymer samples on both side surfaces homogeneously improved the Charpy impact value $\left(a_{\mathrm{uc}}\right) 21 \%$, from 24.6 to $29.8 \mathrm{~kJ} \mathrm{~m}^{-2}$ over the untreated samples at median- $P_{\mathrm{f}}$ of 0.50 ; and at low- $P_{\mathrm{f}}$ of 0.07 improved $18 \%$ from 22.0 to $26.0 \mathrm{~kJ} \mathrm{~m}^{-2}$ indicating
Before EBI

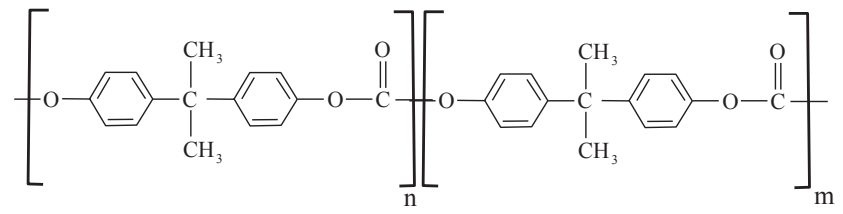

After EBI

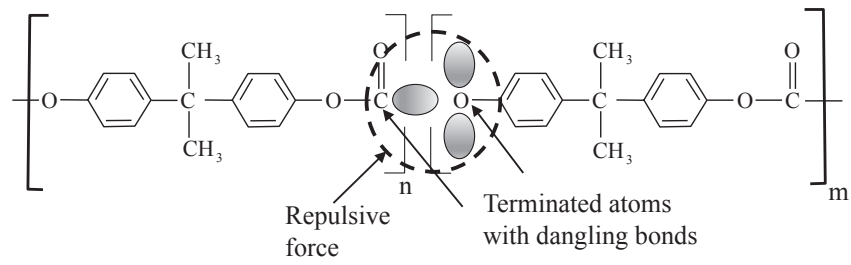

Fig. 6 Schematic nanoscale illustration of polycarbonate polymer before and after EBI.

reliability of parts is possible. At high- $P_{\mathrm{f}}$ of $0.93, a_{\mathrm{uc}}$ was improved $11.3 \%$ from 44.0 to $49.0 \mathrm{~kJ} \mathrm{~m}^{-2}$. The 0.13 MGy-EBI also apparently improved the $a_{\mathrm{uc}}$ at all $P_{\mathrm{f}}$ over the untreated samples while exhibiting a $24 \%$ improvement in average $a_{\mathrm{uc}}$ from 27.3 to $33.8 \mathrm{~kJ} \mathrm{~m}^{-2}$.

(2) For safety, reliability and quality control considerations the $0.13 \mathrm{MGy}-\mathrm{EBI}$ raised the lowest limit of impact value $\left(a_{\mathrm{s}}\right)$ at $P_{\mathrm{f}}=0$ estimated by the 3-parameter Weibull equation $14 \%$ over the untreated samples from 22.0 to $25.5 \mathrm{~kJ} \mathrm{~m}^{-2}$.

(3) Hence, the $0.13 \mathrm{MGy}-\mathrm{EBI}$ appears to be near the optimal dose for Charpy impact resistance of the PC samples raising $a_{\mathrm{uc}}$ values above those of 0.04 and $0.22 \mathrm{MGy}$, and 0.30 to $0.86 \mathrm{MGy}$.

(4) EBI generates dangling bonds where repulsive forces are generated between the active shell electrons at terminated atoms in the PC polymers irradiated near the sample surface, probably inducing relaxation of heterogeneous stress concentration, as well as compressive stress (high molecular density) by microexpansion around terminated atoms increasing the $a_{\mathrm{uc}}$.

(5) Optical observation of PC sample fracture surfaces showed increasing EBI dose increased ductility by decreasing the fractured split ratio, $R_{\mathrm{S}}$ a characterization of the separated portion of the total cross-section from untreated $\left(R_{\mathrm{s}}=0.70\right)$, to $0.86 \mathrm{MGy}\left(R_{\mathrm{s}}=0.15\right)$ as cracks propagates into the thickness from the tensile side. Since in the literature EBI is reported to generate dangling bonds in PC creating micro-expansive forces increasing mechanical properties, the $0.13 \mathrm{MGy}$ dose gave the optimum dangling bond density for impact strength. However, at higher EBI doses above $0.22 \mathrm{MGy}$, excessive dangling bond generation appeared to increase ductility in the form of lowering the split ratio, $R_{\mathrm{S}}$ but weakening the molecular structure allowing chains to slide past each other easier decreasing impact values with less crack propagation. Therefore, carefulness is extremely necessary in quality control to adjust the EBI dose to optimal level when treating for PC aircraft and other parts to maximize safety with high strength. 


\section{Acknowledgements}

Our sincere gratitude goes to Eye Electron Beam Co., Ltd. (Gyoda, Saitama, Japan) for their support with this work, which was partly supported by the JSPS Core-to-Core Program, A. Advanced Research Networks, 'International research core on smart layered materials and structures for energy saving'.

\section{REFERENCES}

1) Y. Nishi, N. Tsuchikura, S. Nanba, T. Yamamoto and M.C. Faudree: Mater. Trans. 53 (2012) 1288-1294.

2) K. Oguri, N. Iwataka, A. Tonegawa, Y. Hirose, K. Takayama and Y. Nishi: J. Mater. Res. 16 (2001) 553-557.

3) K. Oguri, K. Fujita, M. Takahashi, Y. Omori, A. Tonegawa, N. Honda, M. Ochi, K. Takayama and Y. Nishi: J. Mater. Res. 13 (1998) 3368 3371.

4) K. Oguri, N. Iwataka, H. Izumi, A. Tonegawa, K. Takayama and Y. Nishi: Proc. 2nd Japan-France Seminar on Intelligent Materials and Structures, (University of Louis Pasteur Strasbourg, France) (1998) pp. 142-144.

5) K. Oguri, T. Takahashi, A. Kadowaki, A. Tonegawa and Y. Nishi: J. Jpn. Inst. Met. 68 (2004) 537-539.

6) H. Sato, K. Iwata and Y. Nishi: Mater. Trans. 50 (2009) 1859-1863.

7) Y. Nishi, M. Uyama, H. Kwazu, H. Takei, K. Iwata, H. Kudoh and K. Mitsubayashi: Mater. Trans. 53 (2012) 1657-1664.

8) Y. Miyazawa, M. Uyama, S. Ishii, M. Kanda and Y. Nishi: Mater. Trans. 54 (2013) 1166-1170.

9) Y. Nishi, M. Uyama, H. Kawazu, H. Takei, K. Iwata, H. Kudoh and K. Mitsubayashi: Mater. Trans. 53 (2012) 1657-1664.

10) M. Uyama, M. Kanda and Y. Nishi: Mater. Trans. 55 (2014) 566-571.

11) M. Kanda, Y. Miyazawa, M. Uyama and Y. Nishi: Mater. Trans. 54 (2013) 1795-1799.

12) M. Uyama, N. Fujiyama, T. Okada, M. Kanda and Y. Nishi: Mater. Trans. 55 (2014) 561-565.

13) T. Okada, M. Kanda, M.C. Faudree and Y. Nishi: Mater. Trans. 55 (2014) 1587-1590.

14) C. Kubo, A. Yagi, M. Kanda and Y. Nishi: Mater. Trans. 56 (2015) 529-533.

15) C. Kubo, T. Okada, M. Uyama, M. Kanda and Y. Nishi: Mater. Trans. 55 (2014) 1742-1749.

16) K.R. Sridhar and R. Bhat: Novel Techniques and Ideas in Mycology, eds. by K.R. Sridhar, F. Bärlocher and K.D. Hyde, Fungal Diversity Research Series 20 (Fungal Diversity Press, 2008) pp. 271-303.

17) Y. Nishi, T. Toriyama, K. Oguri, A. Tonegawa and K. Takayama:
J. Mater. Res. 16 (2001) 1632-1635.

18) Y. Nishi, M. Mizutani, A. Kimura, T. Toriyama, K. Oguri and A. Tonegawa: J. Mater. Sci. 38 (2003) 2215-2218.

19) Y. Nishi, A. Mizutani and N. Uchida: J. Therm. Compos. Mater. 17 (2004) 289-302.

20) A. Mizutani and Y. Nishi: Mater. Trans. 44 (2003) 1857-1860.

21) Y. Nishi, K. Inoue and M. Salvia: Mater. Trans. 47 (2006) 2846-2851.

22) Y. Nishi, H. Takei, K. Iwata, M. Salvia and A. Vautrin: Mater. Trans. 50 (2009) 2826-2832.

23) H. Takei, K. Iwata, M. Salvia, A. Vautrin and Y. Nishi: Mater. Trans. 51 (2010) 2259-2265.

24) Y. Nishi, R. Ourahmoune, M. Kanda, J. Quan, M.C. Faudree and M. Salvia: Mater. Trans. 55 (2014) 1304-1310.

25) K. Iwata and Y. Nishi: Mater. Trans. 49 (2008) 2058-2062.

26) K. Iwata and Y. Nishi: Mater. Trans. 51 (2010) 121-127.

27) Y. Nishi and K. Iwata: Mater. Trans. 46 (2005) 2241-2245.

28) Y. Nishi, H. Kobayashi and M. Salvia: Mater. Trans. 48 (2007) 19241927.

29) M.C. Faudree, Y. Nishi and M. Gruskiewicz: Mater. Trans. 53 (2012) 1412-1419.

30) T. Takahashi, T. Morishita and Y. Nishi: J. Jpn. Inst. Met. 69 (2005) $759-762$.

31) ASTM D 6264-98 (1998).

32) K. Imielińska, L. Guillaumat, R. Wojtyra and M. Castaings: Compos., Part B 39 (2008) 1034-1041.

33) A.S. Vaidya, U.K. Vaidya and N. Uddin: Mater. Sci. Eng. A 472 (2008) 52-58.

34) O.S. David-West, D.H. Nash and W.M. Banks: Compos. Struct. 83 (2008) 247-258.

35) L. Aktay, A.F. Johnson and M. Holzapfel: Comput. Mater. Sci. 32 (2005) 252-260.

36) K. Komai, K. Minoshima, K. Tanaka and K. Nakaike: 12th International Conference on Composite Materials, Paris 1999, paper 1286, 1-10.

37) M. Aktaș, R. Karakuzu and Y. Arman: Compos. Struct. 89 (2009) 7782.

38) S.-L. Gao and J.-K. Kim: Compos., Part A 32 (2001) 775-785.

39) V. Kostopoulos, A. Baltopoulos, P. Karapappas, A. Vavouliotis and A. Paipetis: Compos. Sci. Technol. 70 (2010) 553-563.

40) J.D. Splett, H.K. Iyer, C.-M. Wang and C.N. McCowan: National Institute of Standards and Technology (NIST) Recommended Practice Guide, Computing Uncertainty for Charpy Impact Test Machine Test Results; Special publication 960-18, US Department of Commerce: Boulder, Colorado (2008) pp. 27-29.

41) Japanese Industrial Standards Committee: JIS K 7077 (1991).

42) K. Komai, K. Minoshima and K. Tanaka: Trans. Jpn. Soc. Mech. Eng. A 64 (1998) 2300-2307.

43) W. Weibull: Ingeniörs vetenskaps akademien, nr. 151 (Generalstabens litografiska anstalts förlag, Stockholm, 1939) pp. 12-14. 